\title{
Photostimulation of male broiler breeders to different photoperiods
}

\author{
M.H. Floyd \& N.C. Tyler ${ }^{\#}$ \\ Animal and Poultry Science, School of Agricultural Sciences and Agribusiness, University of KwaZulu-Natal, \\ Scottsville 3209, South Africa
}

Copyright resides with the authors in terms of the Creative Commons Attribution 2.5 South African Licence.

See: http://creativecommons.org/licenses/by/2.5/za/

Condition of use: The user may copy, distribute, transmit and adapt the work, but must recognise the authors and the South African Journal of Animal Science

\begin{abstract}
The effect of photostimulation of male broiler breeders $(n=144)$ to different photoperiods $(8-\mathrm{h}$ control and $9,9.5,10,10.5,11,11.5,12,12.5,13,14$ and $18 \mathrm{~h}$ ) applied at 20 weeks of age, on age at first semen production, testis weights, as predicted by comb area, and semen characteristics at the reported age at first egg of females provided the same photostimulation photoperiods, as well as semen characteristics during the production cycle and comb area and testis weights at 51 weeks, was investigated. Photostimulation photoperiod did not affect age at first semen production, sperm motility, morphology or predicted testis weights. Sperm concentration, at the reported age at first egg of females on the same photostimulation photoperiod, decreased with increasing photostimulation photoperiod. Large variation in the male response to photostimulation was observed, however, photostimulation to $12 \mathrm{~h}$ or higher resulted in reduced variation in the age at first semen production. Males provided with the longer photostimulatory photoperiods had smaller testis weights at 51 weeks of age, although this was not associated with decreased sperm concentration, increased abnormal sperm morphology or reduced comb area. When male and female broiler breeders are reared on the same lighting regimen, initial male reproductive potential is not adversely affected, provided that the photostimulation photoperiod does not exceed the saturation daylength of $13 \mathrm{~h}$, above which, sperm concentration is lower at the reported female age at first egg, which could negatively affect egg fertility near peak production, and the onset of adult photorefractoriness appears to be advanced, which could negatively affect egg fertility towards the end of production.
\end{abstract}

Keywords: Testosterone, comb area, cockerel, lighting regime, fertility

\#Corresponding author: tyler@ukzn.ac.za

\section{Introduction}

Photorefractoriness is a mechanism in seasonal birds that limits reproductive activity to times in the year that optimise successful rearing of offspring. The juvenile form, which prevents breeding in the same year as hatch, is dissipated on exposure to short days. In birds that show the absolute form of photorefractoriness, such as the Red-legged partridge, sexual maturation is prevented until exposure to short days (Woodard et al., 1980), while in broiler breeders that exhibit a relative form of photorefractoriness, sexual maturity is not prevented, but rather delayed if there is no exposure to short days (Lewis et al., 2003; Tyler \& Gous, 2008). The adult form terminates reproductive activity after prolonged exposure to long days. The critical daylength (photoperiod required to effect a change) in dwarf broiler breeders was found to be less than $10.5 \mathrm{~h}$ and the saturation daylength (photoperiod above which no further advance in maturity is observed) was between 10.5 and 12.75 h (Dunn \& Sharp, 1990). Lewis et al. (2008) determined the critical and saturation daylengths more accurately in female broiler breeders as 9.5 and $13 \mathrm{~h}$, respectively. The onset of adult photorefractoriness appears to be advanced in broiler breeders maintained on long days (Lewis et al., 2003; Tyler \& Gous, 2008) or if photoperiodic increments are provided during lay (Lewis \& Gous, 2006).

There is adequate literature confirming that broiler breeder females exhibit photorefractoriness (Lewis et al., 2003; Lewis et al., 2004; Lewis \& Gous, 2006), and while Tyler \& Gous (2008) confirmed the same 
phenomenon in males reared on constant photoperiods, there is evidence to suggest that turkey males do not exhibit photorefractoriness (Proudman \& Siopes, 2005), while turkey females do (Proudman, 1998).

The aim of this experiment was to identify the effect of different photostimulation photoperiods, applied from 20 weeks of age, on the age at first semen production, testis weights, as predicted by comb area, and semen characteristics of male broiler breeders at the reported age when females reared under the same conditions, and photostimulated to the same photoperiods, achieve sexual maturity as well as to determine the rate of development of adult photorefractoriness towards the end of the production cycle.

An understanding of this would allow for the design of lighting programmes that optimize male fertility during the peak egg production period in females.

\section{Materials and Methods}

One hundred and forty four, 15 week old, commercially reared broiler breeder males (female-line Cobb grand-parent stock) from light-tight facilities (raised on a 9-h photoperiod) were housed on litter in 12 light-tight rooms (two suites of six rooms each), with each room subdivided into 12 individual wire pens (60 $\mathrm{cm}$ wide x $44 \mathrm{~cm}$ deep x $60 \mathrm{~cm}$ high). Birds were randomly allotted to cages and weighed, and the weights subjected to an ANOVA (Genstat, 2008) which showed no significant differences in average body weights between rooms. Each bird received $120 \mathrm{~g} / \mathrm{d}$ of a pelleted commercial broiler breeder grower diet throughout the trial. Birds had ad libitum access to water. During the period of acclimatisation (period of housing at 15 weeks to age to photostimulation at 20 weeks of age), an 8-h photoperiod (07:00 -15:00) was implemented in each room. A $60 \mathrm{~W}$ incandescent lamp, located $1.8 \mathrm{~m}$ above the floor, was used in each room to provide illumination giving a mean illuminance of $47 \pm 1.8$ lux. At 20 weeks of age, the photoperiod was increased in each room, excluding the non-photostimulated control, to $9,9.5,10,10.5,11,11.5,12,12.5,13,14$ and 18 h. A wide range in treatments to provide a more accurate regression curve was considered to be more important than the replication of treatments.

Semen training was performed on the birds twice weekly starting from the week of arrival, and the date of first semen production was recorded. Two days prior to the corresponding reported mean age at first egg of females on the same treatment (Lewis et al., 2008), semen was collected from the male birds, using a modified version of the method of Lake (1957), and assessed for concentration, motility and morphology, and the number of days in production. The difference between the first semen production to the corresponding reported mean age at first egg of females on the same treatment (Lewis et al., 2008) was calculated. Sperm concentration was measured with the use of a haemocytometer. Morphology was assessed after fixing in 3\% glutaldehyde and counting 100 sperm under a light microscope with an oil immersion lens at $100 \mathrm{x}$ magnification. The number of normal sperm and those with abnormalities were recorded.

At the corresponding reported female age at first egg from females on the same treatments (Lewis et al., 2008), digital photographs were taken of the left and right side of the head of each male. Each picture contained a centimetre ruler for image calibration and the computer mouse was used to trace the perimeter of the comb in the digital photograph of the clearest side of each bird in order to calculate the comb area using image analysis software (Rasband, 2006). The comb area was used to predict the average testis weight of each bird (Tyler \& Gous, 2008).

Semen samples were also collected at 33, 45 and 51 weeks of age and the sperm concentration, motility and morphology assessed as previously. At 40, 45 and 51 weeks of age semen was collected for artificial insemination, the concentration calculated, and diluted with Tyrodes solution to ensure a concentration of $30 \times 10^{6}$ sperm per insemination of two to three commercial hens per male. Eggs were collected and stored in a cold room and the number of sperm trapped in the outer perivitelline layer (OPVLsperm) were later counted using the method described by Wishart (1987) from eggs collected on days 3, 5, 6 and 8 post-insemination for week 40 and days $4,6,8$ and 13 post-insemination for weeks 45 and 51 (as there was no difference between the day 3 and 5 count at 40 weeks). If eggs were found to be infertile on day 8 post-insemination, the eggs on day 13 were not analysed and assumed to be infertile. The number of sperm counted in 20 random fields of view (x10 magnification) was converted into a number per $\mathrm{mm}^{2}$ of membrane and the egg scored as fertile or infertile according to Brillard \& Antoine (1990) who determined that 0.43 sperm per $\mathrm{mm}^{2}$ of membrane were needed for $100 \%$ probability of fertility of an egg.

Comb area was measured again at 51 weeks of age. After this the jugular vein was severed, after electrical stunning, of the birds in cages 1 to 5 from each treatment. The testes were removed, weighed and 
the dimensions recorded. Those birds not producing semen were also sacrificed to determine whether testis regression had occurred. The presence or absence of semen in the vas deferens was recorded.

The age at first semen production of males on different photoperiodic treatments was subjected to an analysis of variance, despite lack of replication, to be able to compare age at sexual maturity results to those obtained by Lewis et al. (2008) for females. Standard curve regression analysis was used to obtain the relationship between sperm concentration and photostimulation photoperiod. No further analyses of variation were performed due to lack of replication. All comb and semen characteristics were subjected to standard curve regression to determine if there was a response to photoperiod. Due to the lack of any significant response, data was reported in tables.

Considering that a semen sample is the combination of semen produced by both testes, the mean testis weight was regressed on photoperiod using a model that divided the data either side of a hinge point (found by iteration) with lines fitted separately above and below the hinge (Lewis et al., 2003) The students t-test was used to compare predicted and actual testis weights at slaughter, as well as to compare the left and right testis weights. Correlations between comb area and mean testis weight were performed. Genstat $11^{\text {th }}$ edition (Genstat, 2008) was used for all statistical analyses.

Ethical approval by the University of KwaZulu-Natal Ethics Committee was obtained prior to the onset of the experiment.

\section{Results and Discussion}

Male broiler breeders in this experiment appeared to begin semen production at the same age, regardless of the photostimulation photoperiod (Table 1). This supports the findings of Brake (1990) and suggests that male broiler breeders display a lower threshold for photostimulation when compared with females. In females, the maximum advance in age at first egg was achieved by transferring birds from an 8 to a 13-h photoperiod, while photoperiods longer than $13 \mathrm{~h}$ produced no further advance in age at first egg (Lewis et al., 2008), which led to a greater difference between first semen production and first egg in birds on the shorter photoperiods.

Table 1 Mean \pm SEM age at first semen production of male, and mean age at first egg of female, broiler breeders transferred at 20 weeks from $8 \mathrm{~h}$ to various photoperiods between 9 and $18 \mathrm{~h}$, with the difference in days between the mean male age at first semen production and the mean age at first egg

\begin{tabular}{cccc}
\hline $\begin{array}{c}\text { Photostimulation } \\
\text { Photoperiod }(\mathrm{h})\end{array}$ & $\begin{array}{c}\text { Mean age at first semen } \\
\text { production }(\mathrm{d})\end{array}$ & $\begin{array}{c}\text { Mean age at first } \\
\text { egg* }(\mathrm{d})\end{array}$ & Difference (d) \\
\hline 8.0 & $162.2^{\mathrm{a}} \pm 2.8$ & $200.4^{\mathrm{a}} \pm 2.0$ & 38 \\
9.0 & $155.3^{\mathrm{a}} \pm 2.0$ & $198.3^{\mathrm{a}} \pm 3.0$ & 43 \\
9.5 & $159.9^{\mathrm{a}} \pm 2.3$ & $194.7^{\mathrm{ab}} \pm 2.6$ & 35 \\
10.0 & $163.9^{\mathrm{a}} \pm 2.6$ & $197.7^{\mathrm{a}} \pm 2.5$ & 34 \\
10.5 & $158.7^{\mathrm{a}} \pm 1.4$ & $192.7^{\mathrm{abc}} \pm 2.4$ & 34 \\
11.0 & $160.3^{\mathrm{a}} \pm 1.9$ & $184.5^{\mathrm{cd}} \pm 2.2$ & 24 \\
11.5 & $167.1^{\mathrm{a}} \pm 3.0$ & $185.7^{\mathrm{bcd}} \pm 2.0$ & 19 \\
12.0 & $160.4^{\mathrm{a}} \pm 1.0$ & $181.9^{\mathrm{d}} \pm 1.4$ & 22 \\
12.5 & $159.4^{\mathrm{a}} \pm 1.0$ & $179.9^{\mathrm{d}} \pm 1.7$ & 20 \\
13.0 & $159.6^{\mathrm{a}} \pm 1.1$ & $182.9^{\mathrm{cd}} \pm 2.3$ & 23 \\
14.0 & $162.1^{\mathrm{a}} \pm 1.3$ & $181.8^{\mathrm{d}} \pm 2.1$ & 20 \\
18.0 & $160.3^{\mathrm{a}} \pm 1.1$ & $177.4^{\mathrm{d}} \pm 1.1$ & 17 \\
& & & \\
\hline
\end{tabular}

\footnotetext{
${ }^{\mathrm{a}, \mathrm{b}, \mathrm{c}, \mathrm{d}}$ Within a column, means without a common superscript differ significantly $(P<0.05)$.

*Data from Lewis et al. (2008).
} 
Sperm concentration at the corresponding reported female age at first egg was, however, significantly affected $(P<0.05)$ by photostimulation photoperiod where a decrease was observed with an increase in photostimulation photoperiod (Figure 1) with the highest concentration recorded from birds on the 8- to 11-h photoperiods, above which, the concentration decreased to reach a plateau from $13 \mathrm{~h}$ onwards.

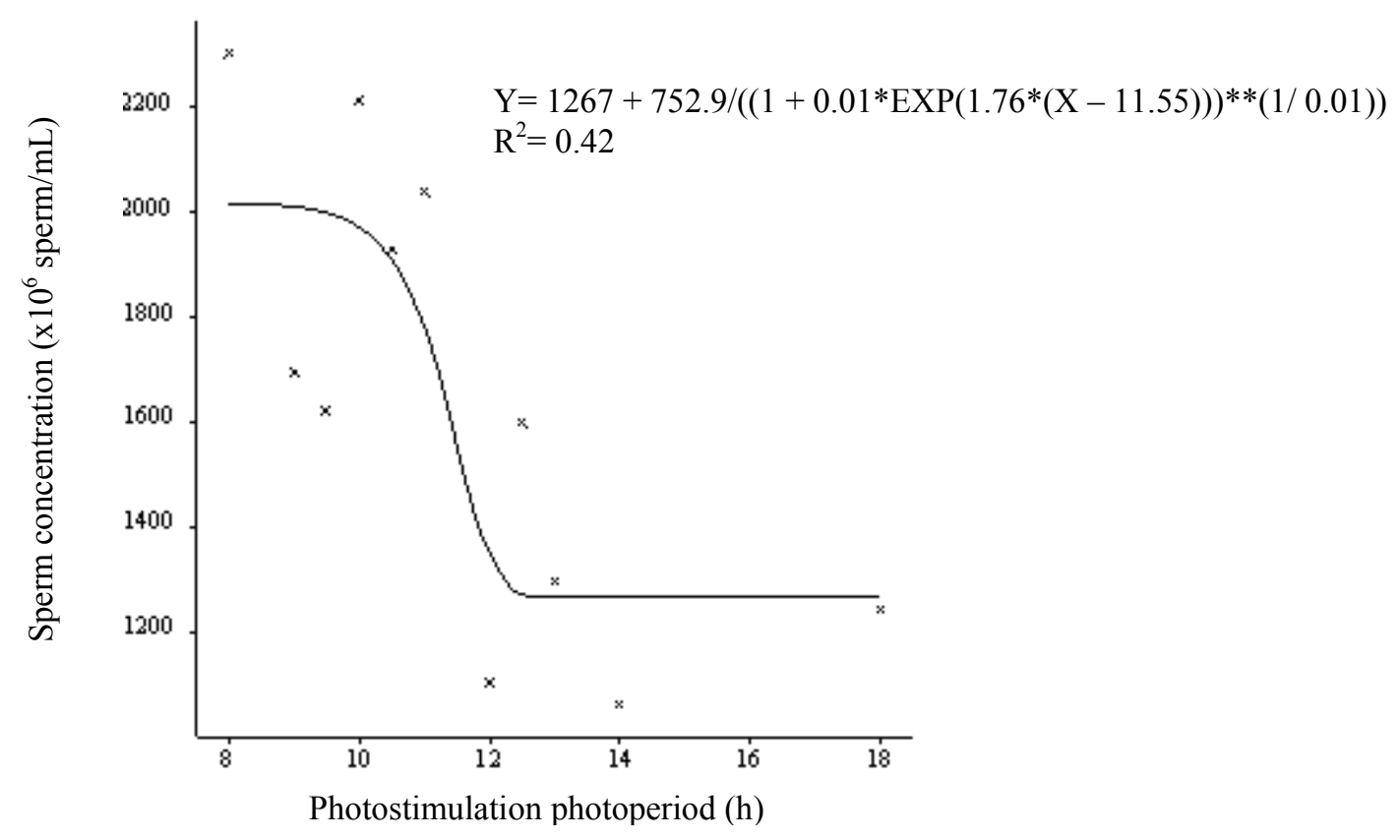

Figure 1 The effect of the photostimulation photoperiod, applied at 20 weeks of age, on semen concentration of male broiler breeders at the reported female age at first egg (Lewis et al., 2008) of birds on the same treatments.

Table 2 Mean \pm SEM (n) semen motility, morphology and predicted testis weight of broiler breeders transferred at 20 weeks of age from $8 \mathrm{~h}$ to various photoperiods between 9 and $18 \mathrm{~h}$, at the reported age at first egg of female broiler breeders on the same photoperiods

\begin{tabular}{cccr}
\hline $\begin{array}{c}\text { Photostimulation } \\
\text { Photoperiod (h) }\end{array}$ & $\begin{array}{c}\text { Mean normal semen } \\
\text { motility (\%) }\end{array}$ & $\begin{array}{c}\text { Mean normal semen } \\
\text { morphology (\%) }\end{array}$ & $\begin{array}{c}\text { Predicted average } \\
\text { testis weight (g) }\end{array}$ \\
\hline 8.0 & $69.7 \pm 5.1(6)$ & $54.0 \pm 3.8(7)$ & $7.5 \pm 1.5(11)$ \\
9.0 & $54.4 \pm 7.0(9)$ & $49.8 \pm 1.9(9)$ & $11.1 \pm 1.5(11)$ \\
9.5 & $70.0 \pm 3.2(6)$ & $22.5 \pm 3.5(4)$ & $8.0 \pm 1.9(11)$ \\
10.0 & $64.0 \pm 4.6(10)$ & $45.9 \pm 3.0(11)$ & $6.9 \pm 1.2(12)$ \\
10.5 & $65.6 \pm 4.0(9)$ & $62.5 \pm 2.3(10)$ & $10.1 \pm 1.1(11)$ \\
11.0 & $75.6 \pm 1.0(9)$ & $48.4 \pm 4.4(11)$ & $10.8 \pm 1.7(12)$ \\
11.5 & $78.1 \pm 2.5(8)$ & $65.5 \pm 4.9(10)$ & $8.3 \pm 1.6(11)$ \\
12.0 & $70.9 \pm 3.4(11)$ & $61.6 \pm 5.6(11)$ & $8.5 \pm 1.5(12)$ \\
12.5 & $77.7 \pm 2.2(7)$ & $33.6 \pm 4.9(10)$ & $10.9 \pm 1.6(11)$ \\
13.0 & $64.0 \pm 4.6(10)$ & $47.6 \pm 3.7(11)$ & $9.4 \pm 1.7(11)$ \\
14.0 & $54.6 \pm 4.7(11)$ & $43.0 \pm 3.2(11)$ & $8.3 \pm 1.6(11)$ \\
18.0 & $65.0 \pm 4.2(8)$ & $42.4 \pm 6.5(11)$ & $8.8 \pm 1.4(11)$ \\
\hline
\end{tabular}


Sperm motility and morphology were not significantly affected by photostimulation photoperiod at the corresponding reported female age at first egg (Table 2). This was probably because considerable variation was observed between males within treatments (Figure 2), which is expected due to the lack of selection pressure directly for male sperm quality traits. This could also have contributed to the lack of a significant effect of the photostimulation photoperiod on the mean age at first semen production of the male broiler breeders. Considering that genetic variation should be similar between all birds, it appears as if the environmental component of variation contributing to the age at first semen production was reduced in birds' photostimulated to $12 \mathrm{~h}$ and above (Figure 2).

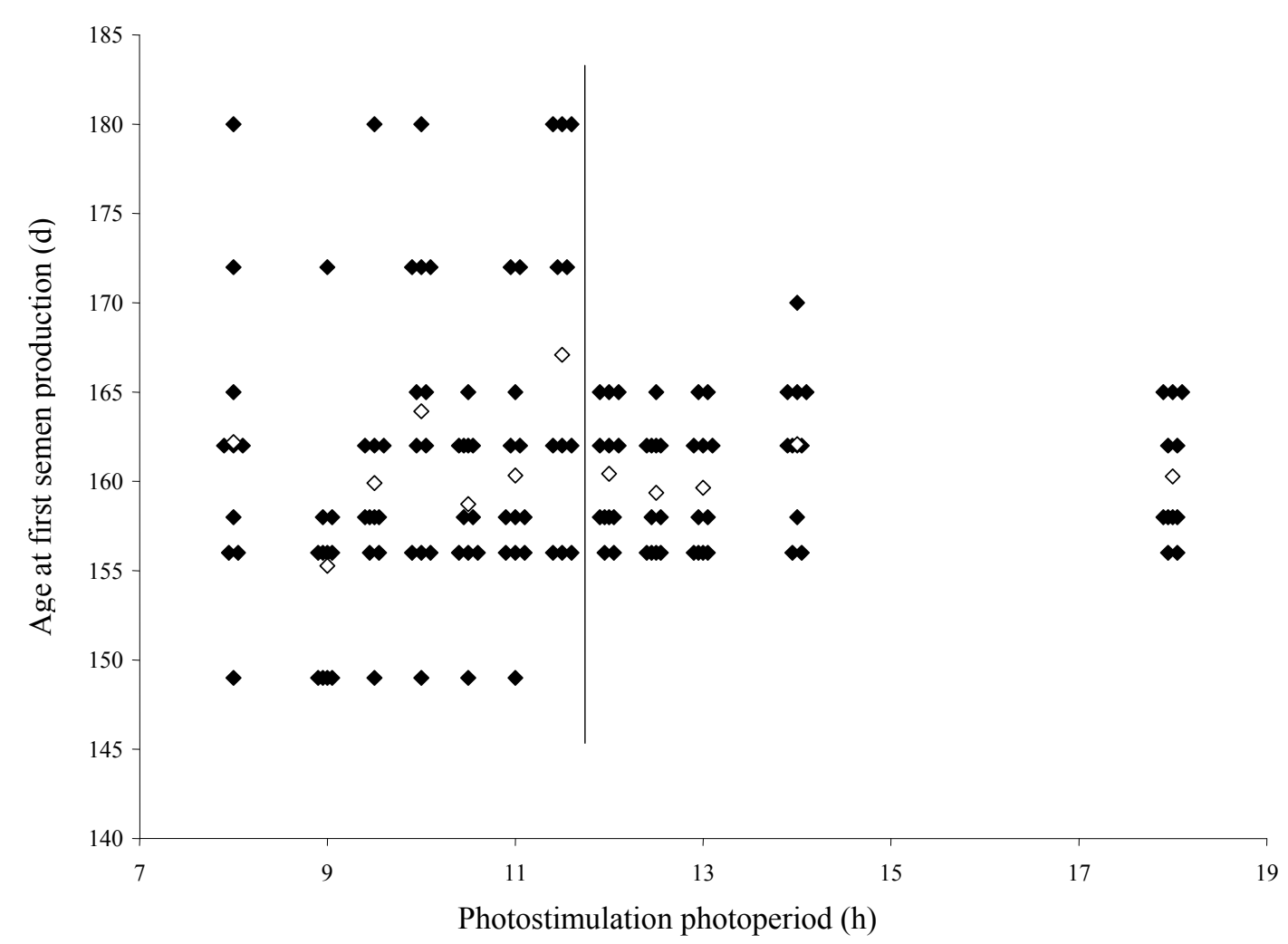

Figure 2 The effect of the photostimulation photoperiod on the individual $(\diamond)$ and mean $(\diamond)$ age at first semen production in male broiler breeders; the line separating two groups of birds with different degrees of variation

Another reason for the lack of a significant effect of photostimulation photoperiod on male age at first semen production is that the first semen samples were obtained at 21.2 weeks of age and, the process of poultry sperm production takes 15 days (De Reviers, 1968). Thus, it was possible that many birds may have been nearing sexual maturity before photostimulation at 20 weeks of age and the birds did not respond to the photostimulation with an advance in age at first semen production. This suggests that males could possibly be photostimulated earlier to elicit a photosexual response.

It is possible that the sperm concentration at the corresponding reported female age at first egg was higher in birds on the shorter photoperiods as the difference in male and female sexual maturity was greater, allowing more time for sexual development in the males before the female age at first egg. However, no relationship was observed between mean sperm concentration and number of days in production (range of 12 to $51 \mathrm{~d}$ ), which implies a photoperiodic rather than an age effect.

There was no relationship between the photostimulation photoperiod and testis weight, as predicted from the comb area of males at the corresponding reported female age at first egg (Table 2). Again, this was probably because all males had reached sexual maturation at the corresponding female age at first egg. 
No photoperiodic response curve was observed in sperm concentration or morphology of the male broiler breeders at 33, 40, 45 or 51 weeks of age, but again there was high within-treatment variation (Table 3). The high variation and lack of photoperiodic response suggest that there are factors additional to photoperiod controlling semen production.

Table 3 Mean \pm SEM (n) sperm concentration and morphology of broiler breeders at 33, 45 and 51 weeks of age after transfer at 20 weeks of age from $8 \mathrm{~h}$ to various photoperiods between 9 and $18 \mathrm{~h}$

\begin{tabular}{|c|c|c|c|c|c|c|c|}
\hline $\begin{array}{l}\text { Photostimulation } \\
\text { photoperiod (h) }\end{array}$ & & $\begin{array}{r}\text { Mean sper1 } \\
\left(\times 10^{6}\right. \\
\end{array}$ & $\begin{array}{l}\text { concentration } \\
\text { erm } / \mathrm{mL} \text { ) }\end{array}$ & & Mean $n$ & $\begin{array}{c}\text { rmal sperm } 1 \\
(\%)\end{array}$ & norphology \\
\hline Age (weeks) & 33 & 40 & 45 & 51 & 33 & 45 & 51 \\
\hline 8.0 & $\begin{array}{l}1958 \pm 201 \\
(\mathrm{n}=4)\end{array}$ & $\begin{array}{l}3382 \pm 502 \\
(\mathrm{n}=7)\end{array}$ & $\begin{array}{l}2858 \pm 417 \\
(\mathrm{n}=8)\end{array}$ & $\begin{array}{l}2659 \pm 273 \\
(\mathrm{n}=9)\end{array}$ & $\begin{array}{l}74.0 \pm 1.9 \\
(\mathrm{n}=5)\end{array}$ & $\begin{array}{l}65.5 \pm 5.1 \\
(\mathrm{n}=11)\end{array}$ & $\begin{array}{l}78.2 \pm 4.2 \\
(\mathrm{n}=9)\end{array}$ \\
\hline 9.0 & $\begin{array}{l}1066 \pm 177 \\
(\mathrm{n}=4)\end{array}$ & $\begin{array}{l}1584 \pm 500 \\
(\mathrm{n}=5)\end{array}$ & $\begin{array}{l}1501 \pm 189 \\
(\mathrm{n}=8)\end{array}$ & $\begin{array}{l}1660 \pm 119 \\
(\mathrm{n}=8)\end{array}$ & $\begin{array}{l}86.7 \pm 3.1 \\
(\mathrm{n}=6)\end{array}$ & $\begin{array}{l}77.5 \pm 4.0 \\
(n=8)\end{array}$ & $\begin{array}{l}67.1 \pm 4.2 \\
(\mathrm{n}=8)\end{array}$ \\
\hline 9.5 & $\begin{array}{l}1521 \pm 153 \\
(\mathrm{n}=10)\end{array}$ & $\begin{array}{l}3913 \pm 310 \\
(\mathrm{n}=7)\end{array}$ & $\begin{array}{l}1925 \pm 235 \\
(\mathrm{n}=6)\end{array}$ & $\begin{array}{l}1622 \pm 123 \\
(\mathrm{n}=9)\end{array}$ & $\begin{array}{l}69.8 \pm 2.8 \\
(\mathrm{n}=9)\end{array}$ & $\begin{array}{l}76.4 \pm 3.5 \\
(n=9)\end{array}$ & $\begin{array}{l}66.7 \pm 5.2 \\
(\mathrm{n}=9)\end{array}$ \\
\hline 10.0 & $\begin{array}{l}1015 \pm 176 \\
(\mathrm{n}=8)\end{array}$ & $\begin{array}{l}1699 \pm 498 \\
(n=4)\end{array}$ & $\begin{array}{l}1559 \pm 155 \\
(\mathrm{n}=7)\end{array}$ & $\begin{array}{l}2006 \pm 205 \\
(\mathrm{n}=9)\end{array}$ & $\begin{array}{l}81.3 \pm 3.8 \\
(\mathrm{n}=8)\end{array}$ & $\begin{array}{l}86.6 \pm 2.8 \\
(\mathrm{n}=8)\end{array}$ & $\begin{array}{l}77.3 \pm 3.2 \\
(\mathrm{n}=9)\end{array}$ \\
\hline 10.5 & $\begin{array}{l}1620 \pm 81 \\
(\mathrm{n}=8)\end{array}$ & $\begin{array}{l}3506 \pm 364 \\
(\mathrm{n}=8)\end{array}$ & $\begin{array}{l}1918 \pm 177 \\
(\mathrm{n}=10)\end{array}$ & $\begin{array}{l}2376 \pm 387 \\
(\mathrm{n}=8)\end{array}$ & $\begin{array}{l}75.5 \pm 2.4 \\
(\mathrm{n}=8)\end{array}$ & $\begin{array}{l}74.3 \pm 7.7 \\
(n=9)\end{array}$ & $\begin{array}{l}71.7 \pm 5.9 \\
(\mathrm{n}=7)\end{array}$ \\
\hline 11.0 & $\begin{array}{l}922 \pm 127 \\
(\mathrm{n}=8)\end{array}$ & $\begin{array}{l}2690 \pm 391 \\
(n=5)\end{array}$ & $\begin{array}{l}1864 \pm 158 \\
(n=11)\end{array}$ & $\begin{array}{l}1776 \pm 186 \\
(\mathrm{n}=9)\end{array}$ & $\begin{array}{l}80.6 \pm 1.9 \\
(\mathrm{n}=9)\end{array}$ & $\begin{array}{l}81.7 \pm 2.5 \\
(\mathrm{n}=12)\end{array}$ & $\begin{array}{l}71.8 \pm 5.8 \\
(\mathrm{n}=8)\end{array}$ \\
\hline 11.5 & $\begin{array}{l}1709 \pm 122 \\
(\mathrm{n}=9)\end{array}$ & $\begin{array}{l}3725 \pm 460 \\
(\mathrm{n}=6)\end{array}$ & $\begin{array}{l}2362 \pm 170 \\
(n=7)\end{array}$ & $\begin{array}{l}2237 \pm 165 \\
(\mathrm{n}=6)\end{array}$ & $\begin{array}{l}81.7 \pm 2.2 \\
(\mathrm{n}=9)\end{array}$ & $\begin{array}{l}87.1 \pm 3.3 \\
(\mathrm{n}=7)\end{array}$ & $\begin{array}{l}80.7 \pm 2.4 \\
(\mathrm{n}=6)\end{array}$ \\
\hline 12.0 & $\begin{array}{l}1375 \pm 289 \\
(\mathrm{n}=8)\end{array}$ & $\begin{array}{l}2520 \pm 470 \\
(n=6)\end{array}$ & $\begin{array}{l}1397 \pm 122 \\
(\mathrm{n}=8)\end{array}$ & $\begin{array}{l}1798 \pm 263 \\
(n=7)\end{array}$ & $\begin{array}{l}75.0 \pm 4.2 \\
(\mathrm{n}=9)\end{array}$ & $\begin{array}{l}81.9 \pm 2.3 \\
(\mathrm{n}=9)\end{array}$ & $\begin{array}{l}75.1 \pm 3.8 \\
(\mathrm{n}=9)\end{array}$ \\
\hline 12.5 & $\begin{array}{l}1472 \pm 84 \\
(\mathrm{n}=9)\end{array}$ & $\begin{array}{l}2611 \pm 282 \\
(n=6)\end{array}$ & $\begin{array}{l}1619 \pm 115 \\
(\mathrm{n}=5)\end{array}$ & $\begin{array}{l}1542 \pm 79 \\
(\mathrm{n}=9)\end{array}$ & $\begin{array}{l}76.7 \pm 2.8 \\
(\mathrm{n}=9)\end{array}$ & $\begin{array}{l}66.7 \pm 5.1 \\
(n=6)\end{array}$ & $\begin{array}{l}82.1 \pm 3.0 \\
(\mathrm{n}=9)\end{array}$ \\
\hline 13.0 & $\begin{array}{l}1210 \pm 156 \\
(\mathrm{n}=10)\end{array}$ & $\begin{array}{l}3053 \pm 305 \\
(\mathrm{n}=7)\end{array}$ & $\begin{array}{l}1912 \pm 217 \\
(\mathrm{n}=8)\end{array}$ & $\begin{array}{l}1904 \pm 134 \\
(\mathrm{n}=9)\end{array}$ & $\begin{array}{l}76.8 \pm 3.1 \\
(\mathrm{n}=10)\end{array}$ & $\begin{array}{l}85.9 \pm 1.9 \\
(\mathrm{n}=10)\end{array}$ & $\begin{array}{l}70.4 \pm 6.8 \\
(\mathrm{n}=8)\end{array}$ \\
\hline 14.0 & $\begin{array}{l}1692 \pm 270 \\
(\mathrm{n}=8)\end{array}$ & $\begin{array}{l}1918 \pm 321 \\
(\mathrm{n}=5)\end{array}$ & $\begin{array}{l}1624 \pm 227 \\
(n=5)\end{array}$ & $\begin{array}{l}1910 \pm 308 \\
(\mathrm{n}=6)\end{array}$ & $\begin{array}{l}78.0 \pm 2.6 \\
(\mathrm{n}=8)\end{array}$ & $\begin{array}{l}75.6 \pm 2.4 \\
(\mathrm{n}=7)\end{array}$ & $\begin{array}{l}64.0 \pm 4.7 \\
(\mathrm{n}=6)\end{array}$ \\
\hline 18.0 & $\begin{array}{l}835 \pm 76 \\
(n=4)\end{array}$ & $\begin{array}{l}257 \pm 314 \\
(\mathrm{n}=7)\end{array}$ & $\begin{array}{l}1882 \pm 97 \\
(\mathrm{n}=9)\end{array}$ & $\begin{array}{l}1558 \pm 161 \\
(\mathrm{n}=9)\end{array}$ & $\begin{array}{l}63.7 \pm 6.5 \\
(\mathrm{n}=6)\end{array}$ & $\begin{array}{l}66.8 \pm 3.0 \\
(\mathrm{n}=9)\end{array}$ & $\begin{array}{l}68.0 \pm 6.3 \\
(\mathrm{n}=8)\end{array}$ \\
\hline
\end{tabular}

The OPVL-sperm in this experiment ranged from 0 to $17 / \mathrm{mm}^{2}$ over the duration of the experiment. Wishart (1987) assumed the radius of an average egg to be $15 \mathrm{~mm}$, resulting in the total area of the PL to be approximately $2829 \mathrm{~mm}^{2}$. Thus, $17 \mathrm{OPVL}$-sperm $/ \mathrm{mm}^{2}$ from a bird inseminated with $30 \times 10^{6}$ sperm would result in approximately 48093 OPVL-sperm, which accounts for only $0.16 \%$ of the sperm inseminated. Wishart (1987) also found that, after insemination with $60 \times 10^{6}$ sperm, the first egg laid contained about $0.2 \%$ of the inseminated sperm in the membrane. This figure may be dependent on the number of sperm which enter the oviduct and the capacity of the sperm storage tubules. After insemination, less than $1 \%$ of the inseminated sperm are selected for transport to, and entry into, the sperm storage tubules and the sperm storage efficiency is logarithmically dependent on the number of sperm inseminated (Brillard \& Bakst, 1990; Brillard, 1993). The initial quantity and quality of sperm at the time of insemination directly influences the degree of selection exerted by the hen on the subsequent numbers of sperm stored in the sperm storage tubules (Brillard, 2003). As the quantity was fixed, this test should provide a measure of the quality of sperm. The results showed no consistent photoperiodic response to fertilising ability of the sperm (Table 4). While the probability of a fertile egg tended to decrease with age, to which the hen age may have also played a role, and days post-insemination, there was a general decline in the probability of fertile egg with an increase in photoperiod at 40 and 45 weeks, although not at 51 weeks. 
Table 4 Percentage probability of a fertile egg after insemination with $30 \times 10^{6}$ sperm from males at 40,45 and 51 weeks of age after transfer at 20 weeks of age from $8 \mathrm{~h}$ to various photoperiods between 9 and $18 \mathrm{~h}$

\begin{tabular}{|c|c|c|c|c|}
\hline \multirow{3}{*}{ Photostimulation photoperiod (h) } & \multicolumn{4}{|c|}{ Probability of a fertile egg } \\
\hline & \multicolumn{4}{|c|}{ Day post-insemination } \\
\hline & 4 & 6 & 8 & 13 \\
\hline \multicolumn{5}{|l|}{40 weeks } \\
\hline 8.0 & 0.96 & 0.99 & 0.85 & 0.68 \\
\hline 9.0 & 0.96 & 0.99 & 0.83 & 0.67 \\
\hline 9.5 & 0.97 & 0.99 & 0.82 & 0.66 \\
\hline 10.0 & 0.97 & 0.98 & 0.81 & 0.66 \\
\hline 10.5 & 0.97 & 0.98 & 0.80 & 0.65 \\
\hline 11.0 & 0.97 & 0.98 & 0.79 & 0.64 \\
\hline 11.5 & 0.97 & 0.97 & 0.78 & 0.64 \\
\hline 12.0 & 0.97 & 0.97 & 0.77 & 0.63 \\
\hline 12.5 & 0.97 & 0.96 & 0.75 & 0.62 \\
\hline 13.0 & 0.97 & 0.95 & 0.74 & 0.62 \\
\hline 14.0 & 0.97 & 0.94 & 0.71 & 0.60 \\
\hline 18.0 & 0.98 & 0.79 & 0.58 & 0.55 \\
\hline \multicolumn{5}{|l|}{45 weeks } \\
\hline 8.0 & 0.99 & 0.98 & 0.85 & 0.00 \\
\hline 9.0 & 0.98 & 0.97 & 0.82 & 0.00 \\
\hline 9.5 & 0.98 & 0.97 & 0.81 & 0.00 \\
\hline 10.0 & 0.97 & 0.96 & 0.79 & 0.00 \\
\hline 10.5 & 0.97 & 0.95 & 0.77 & 0.00 \\
\hline 11.0 & 0.96 & 0.95 & 0.75 & 0.00 \\
\hline 11.5 & 0.96 & 0.94 & 0.73 & 0.00 \\
\hline 12.0 & 0.95 & 0.93 & 0.71 & 0.00 \\
\hline 12.5 & 0.94 & 0.91 & 0.69 & 0.00 \\
\hline 13.0 & 0.93 & 0.90 & 0.66 & 0.00 \\
\hline 14.0 & 0.90 & 0.87 & 0.61 & 0.00 \\
\hline 18.0 & 0.70 & 0.65 & 0.40 & 0.00 \\
\hline \multicolumn{5}{|l|}{51 weeks } \\
\hline 8.0 & 0.77 & 0.77 & 0.38 & 0.00 \\
\hline 9.0 & 0.75 & 0.78 & 0.44 & 0.00 \\
\hline 9.5 & 0.74 & 0.78 & 0.47 & 0.00 \\
\hline 10.0 & 0.73 & 0.78 & 0.50 & 0.00 \\
\hline 10.5 & 0.72 & 0.79 & 0.53 & 0.00 \\
\hline 11.0 & 0.71 & 0.79 & 0.56 & 0.00 \\
\hline 11.5 & 0.70 & 0.80 & 0.60 & 0.00 \\
\hline 12.0 & 0.69 & 0.80 & 0.62 & 0.00 \\
\hline 12.5 & 0.68 & 0.81 & 0.65 & 0.00 \\
\hline 13.0 & 0.67 & 0.81 & 0.68 & 0.00 \\
\hline 14.0 & 0.65 & 0.82 & 0.73 & 0.00 \\
\hline 18.0 & 0.57 & 0.85 & 0.88 & 0.00 \\
\hline
\end{tabular}


Table 5 Mean \pm SEM (n) comb area of broiler breeders at 51 weeks of age after transfer at 20 weeks of age from $8 \mathrm{~h}$ to various photoperiods between 9 and $18 \mathrm{~h}$

\begin{tabular}{cc}
\hline Photostimulation photoperiod $(\mathrm{h})$ & Comb area $\left(\mathrm{cm}^{2}\right)$ \\
\hline 8.0 & $55.4 \pm 3.2(5)$ \\
9.0 & $70.0 \pm 3.7(6)$ \\
9.5 & $65.1 \pm 7.7(5)$ \\
10.0 & $69.7 \pm 6.3(4)$ \\
10.5 & $66.7 \pm 5.6(7)$ \\
11.0 & $65.7 \pm 2.9(7)$ \\
11.5 & $53.3 \pm 7.6(6)$ \\
12.0 & $55.3 \pm 9.7(6)$ \\
12.5 & $54.6 \pm 8.4(5)$ \\
13.0 & $54.4 \pm 8.4(4)$ \\
14.0 & $48.2 \pm 6.6(4)$ \\
18.0 & $59.3 \pm 8.0(6)$ \\
\hline
\end{tabular}

No photoperiodic response in comb area was observed at 51 weeks of age (Table 5), probably due to large variation recorded in this variable. While comb growth is mediated by testosterone (Hagelin \& Ligon, 2001) and could therefore be considered as an indication of testis weight (Pizzari et al., 2004), comb area is an integration of various factors that influence comb size, as reviewed by Parker \& Ligon (2007).

There was a significant $(P<0.001)$ correlation between comb area and average testis weight $(\mathrm{r}=0.5)$ across all photoperiods. However, the prediction equation for average testis weight using comb area that was developed by Tyler \& Gous (2008) for younger birds and could not be used to accurately predict the testis weights of male broiler breeders at 51 weeks of age. It is possible that there may be a delay between testis regression and comb regression, as not all birds with small testes had regressed combs. It is also possible that in younger birds, because comb growth increases dramatically and is highly correlated with the average testis weight, the relationship is significant. However, comb size reaches a plateau, despite an increase in average testis weight (Tyler \& Gous, 2008), probably due to the immunosuppressive cost of maintenance of the secondary sexual characteristics (Zuk et al., 1995); so it is more likely that the relationship is not significant in older birds.

At 51 weeks of age, the left testis weighed more than the right testis in $67.7 \%$ of the males, which concurs with that found by Hocking (1992). The left and right testis weight was not significantly different for birds on treatments $\leq 11 \mathrm{~h}$, with the exception of those on the 13 and $18 \mathrm{~h}$ treatment. Testis regression had begun in birds on the longer photostimulation photoperiods (Figure 4), and the differences between left and right testis in these treatments were probably because the right testis regressed at a faster rate than the left. A hinge point of the photoperiod effect on average testis weight was obtained at $13 \mathrm{~h}$ (Figure 4).

Four of the 10 birds with an average testis weight of $<10 \mathrm{~g}$, and not producing semen, had also undergone a regression in the area of the comb when compared with the comb area measured at 29 weeks of age.

On average, the testis weight at 51 weeks of age of males on photoperiods $\geq 11.5 \mathrm{~h}$ did not exceed $11 \mathrm{~g}$ whereas in males on photoperiods $\leq 11 \mathrm{~h}$, testis weights were above $14 \mathrm{~g}$. Variation was observed in testis weight from males on the same treatments, where some males within a treatment had undergone testis regression and were no longer producing semen (evident from the lack of semen in the vas deferens), while others showed no signs of impending testes regression.

It was noted that no bird with an average testis weight of $<10 \mathrm{~g}$ produced semen, except for two birds on the $18 \mathrm{~h}$ treatment in which semen was observed in the vas deferens even though the average testis weights were 5.19 and $4.89 \mathrm{~g}$. Of these two birds, the one semen sample was contaminated and thus not 


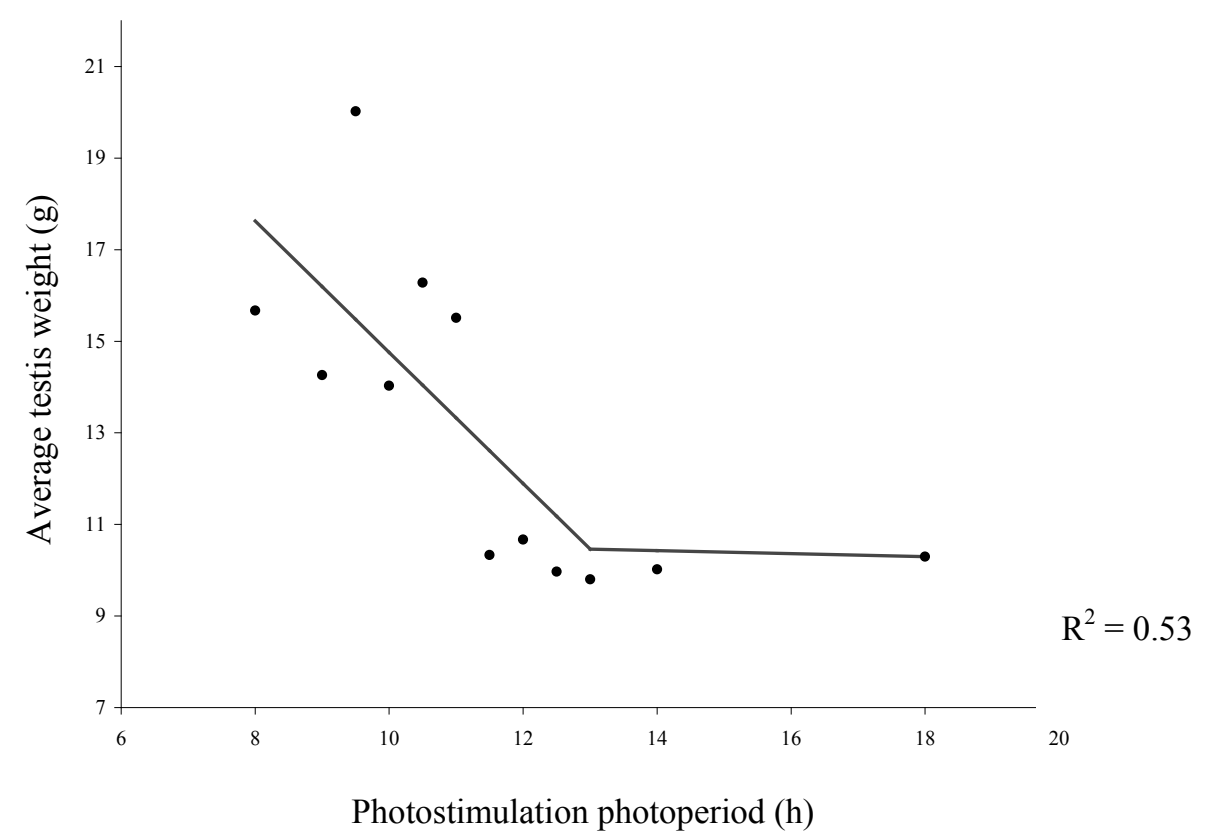

Figure 4 Hinge regression of average testis weight at different photostimulation photoperiods of broiler breeder males at 51 weeks of age.

analysed for semen quality but the other produced a sample which contained the lowest sperm concentration and percentage normal morphology out of all the birds analysed for that treatment. Vizcarra et al. (2004) reported that in male broiler breeders a normal testis size was $>10 \mathrm{~g}$. Sharp et al. (1977) found that only when the testes (average of left and right testis) of birds weighed more than $10 \mathrm{~g}$ was spermatogenesis completed and a significant increase in the mean plasma concentration of testosterone observed.

These findings are in agreement with the results reported in female broiler breeders, where those provided longer photoperiods became photorefractory earlier (Lewis \& Gous, 2006). This confirms, in males, what Lewis et al. (2008) observed in females; that it is unnecessary, and even detrimental, to provide broiler breeders with more than $13 \mathrm{~h}$, as this is past the saturation daylength, where no further advance in age at sexual maturity is observed, and the onset of adult photorefractoriness is hastened.

\section{Conclusions}

These results suggest that, although there is no difference in male age at first semen production of birds provided different photostimulation photoperiods, and no response to photoperiod in predicted testis weight, providing broiler breeder flocks with a photoperiod longer than $13 \mathrm{~h}$ would be unnecessary, and may even be detrimental to egg fertility. This is because, at these photoperiods, male semen concentration is lower at the time the females reach sexual maturity, as maturity in females is advanced with increasing photoperiod after stimulation up to $13 \mathrm{~h}$ in females (Lewis et al., 2008), but not in males.

Although sperm concentration and morphology were not affected by photostimulation photoperiod, the onset of adult photorefractoriness appeared to be advanced in male broiler breeders provided photostimulation photoperiods $>13 \mathrm{~h}$, evidenced by lower average testis weight at 51 weeks of age. Because this response is similar to that found in females (Lewis et al., 2008) it is suggested that broiler breeder flocks should not be photostimulated to photoperiods $>13 \mathrm{~h}$, to delay the onset of adult photorefractoriness and to reduce feed and electricity usage (Lewis \& Morris, 2006). The large degree of variation in measures of male fertility assessed in this experiment implies an opportunity for progress in selection for fertility traits.

Any opinion, findings and conclusions or recommendations expressed in this material are those of the authors and therefore the NRF does not accept and liability in regard thereto.

\section{Acknowledgements}

This material is based upon work supported financially by the National Research Foundation. 


\section{References}

Brake, J., 1990. The effect of a 2-hour increase in photoperiod at 18 weeks of age on broiler breeder performance. Poult. Sci. 69, 910-914.

Brillard, J.-P., 1993. Sperm storage and transport following natural mating and artificial insemination. Poult. Sci. 72, 923-928.

Brillard, J.-P., 2003. Practical aspects of fertility in poultry. Wrld's Poult. Sci. J. 59, 441-446.

Brillard, J.-P. \& Antoine, H., 1990. Storage of sperm in the uterovaginal junction and its incidence on the numbers of spermatozoa present in the perivitelline layer of hen's eggs. Br. Poult. Sci. 31, 635-644.

Brillard, J.-P. \& Bakst, M.R., 1990. Quantification of spermatozoa in the sperm-storage tubules of turkey hens and the relation to sperm numbers in the perivitelline layer of eggs. Biol. Reprod. 43, 271-275.

De Reviers, M., 1968. Determination of the duration of the spermatogenic process in the cockerel using tritiated thymidine (in French). VI Cong. Intern. Reprod. Anim. Insem., Paris.

Dunn, I.C. \& Sharp, P.J., 1990. Photoperiodic requirements for LH release in juvenile broiler and egg-laying strains of domestic chickens fed ad lib or restricted diets. J. Reprod. Fert. 90, 329-335.

Genstat, 2008. Genstat, 11th Edition, VSN International. Hemel Hempstead, UK

Hagelin, J.C. \& Ligon, J.D., 2001. Female quail prefer testosterone-mediated traits, rather than the ornate plumage of males. Anim. Behav. 61, 465-476.

Hocking, P.M., 1992. Bilateral testicular asymmetry and supernumerary testes in the domestic fowl (Gallus domesticus). Br. Poult. Sci. 33, 455-460.

Lake, P.E., 1957. Fowl semen as collected by the massage method. J. Agric. Sci. 49, 120-126.

Lewis, P.D. \& Gous, R.M., 2006. Constant and changing photoperiods in the laying period for broiler breeders allowed normal or accelerated growth during the rearing period. Poult. Sci. 85, 321-325.

Lewis, P.D. \& Morris, T.R., 2006. Poultry Lighting, the theory and practice. Northcot, Andover, U.K.

Lewis, P.D., Ciacciariello, M. \& Gous, R.M., 2003. Photorefractoriness in broiler breeders: Sexual maturity and egg production evidence. Br. Poult. Sci. 44, 634-642.

Lewis, P.D., Backhouse, D. \& Gous, R.M., 2004. Constant photoperiods and sexual maturity in broiler breeder pullets. Br. Poult. Sci. 45, 557-560.

Lewis, P.D., Tyler, N.C., Gous, R.M., Dunn, I.C. \& Sharp, P.J., 2008. Photoperiodic response curves for plasma LH concentrations and age at first egg in female broiler breeders. Anim. Reprod. Sci. 109, 274-286.

Parker, T.H. \& Ligon, J.D., 2007. Multiple aspects of condition influence a heritable sexual trait: a synthesis of the evidence for capture of genetic variance in red junglefowl. Biol. J. Lin. Soc. 92, 651-660.

Pizzari, T., Jensen, P. \& Cornwallis, C.K., 2004. A novel test of the phenotype-linked fertility hypothesis reveals independent components of fertility. Proc. Royal Soc. B 271, 51-58.

Proudman, J.A., 1998. Circulating prolactin levels at the end of the photophase and the end of the scotophase throughout the reproductive cycle of the turkey hen. Poult. Sci. 77, 303-308.

Proudman, J.A. \& Siopes, T.D., 2005. Thyroid hormone and prolactin profiles in male and female turkeys following photostimulation. Poult. Sci. 84, 942-946.

Rasband, J., 2006. Image J. National Institute of Health. USA.

Sharp, P.J., Culbert, J. \& Wells, J.W., 1977. Variations in stored and plasma concentrations of androgens and luteinizing hormone during sexual development in the cockerel. J. Endocrin. 74, 467-476.

Tyler, N.C. \& Gous, R.M., 2008. The effect of constant photoperiod on testis weight and the use of comb area to predict testis weight in broiler breeder males. S. Afr. J. Anim. Sci. 38, 153-158.

Vizcarra, J.A., Kreider, D.L. \& Kirby, J.D., 2004. Episodic gonadotrophin secretion in the mature male fowl: serial blood sampling from unrestrained male broiler breeders (Gallus domesticus). Biol. Reprod. 70, 1798-1805.

Wishart, G.J., 1987. Regulation of the length of the fertile period in the domestic fowl by numbers of oviducal spermatozoa, as reflected by those trapped in laid eggs. J. Reprod. Fert. 80, 493-498.

Woodard, A.E., Abplanalp, H. \& Snyder, R.L., 1980. Photorefractoriness and sexual response in aging partridge kept under constant long- and short-day photoperiods. Poult. Sci. 59, 2145-2150.

Zuk, M., Johnsen, T.S. \& Maclarty, T., 1995. Endocrine-immune interactions, ornaments and mate choice in Red Jungle Fowl. Proc. Royal Soc. London B 260, 205-210. 